Spring 4-22-2016

\title{
Current Therapeutic Role and Medicinal Potential of Scutellaria barbata in Traditional Chinese Medicine and Western Research
}

\section{Geyang Tao}

University of Connecticut - Storrs, athsstar@gmail.com

Marcy J. Balunas

University of Connecticut - Storrs, marcy.balunas@uconn.edu

Follow this and additional works at: https://opencommons.uconn.edu/srhonors_theses

Part of the Alternative and Complementary Medicine Commons, Integrative Medicine Commons, Natural Products Chemistry and Pharmacognosy Commons, and the Oncology

\section{$\underline{\text { Commons }}$}

\section{Recommended Citation}

Tao, Geyang and Balunas, Marcy J., "Current Therapeutic Role and Medicinal Potential of Scutellaria barbata in Traditional Chinese Medicine and Western Research" (2016). Honors Scholar Theses. 481.

https://opencommons.uconn.edu/srhonors_theses/481 


\section{Current Therapeutic Role and Medicinal Potential of Scutellaria barbata in Traditional Chinese Medicine and Western Research}

Geyang Tao

Advisor, Marcy J. Balunas, Ph.D.

Department of Pharmaceutical Sciences

School of Pharmacy Honors Program

University of Connecticut, Storrs, CT 06269 


\begin{abstract}
Ethnopharmacological relevance: Scutellaria barbata is a common herb in Traditional Chinese Medicine (TCM) most often used to treat cancer. S. barbata has been found to exhibit efficacy both in vitro and in vivo on a variety of cancer types. Similarly encouraging results have been shown in patients with metastatic breast cancer from Phase Ia and Ib clinical trials. This study aims to elucidate the current use of $S$. barbata by TCM practitioners and in current Western research.
\end{abstract}

Materials and Methods: Semi-structured interviews were conducted with fifteen TCM practitioners in Beijing and Nanjing, China to understand their clinical use of $S$. barbata. Practitioners were also asked to comment on the future development of TCM using Western research methods and the potential for integration of the two types of medicine in clinical therapy. Statistical analyses were conducted to compare use of S. barbata by disease and in conjunction with other herbs.

Results: Current Western research related to S. barbata is focused on cancer treatment, which corresponds to the most common use of $S$. barbata by TCM practitioners. Other common uses that practitioners reported included infection and inflammation, for which Beijing practitioners reported use of $S$. barbata more often than Nanjing practitioners $(p<0.05)$. Hedyotis diffusa was found to be the most commonly cited herb to pair with $S$. barbata for cancer treatment $(p<0.05)$. When compared to Western clinical trials of BZL101, an S. barbata extract, TCM practitioners reported using smaller doses of $S$. barbata in shorter durations, in combination with numerous other herbs with the goal to potentiate therapeutic efficacy and mitigate side effects. In addition, TCM practitioners repeatedly emphasized symptom differentiating as the key to achieving maximum therapeutic potential of $S$. barbata, a factor typically overlooked in Western research. 
Conclusion: Similarities and differences in diagnosis and treatment regimens between TCM practitioners and Western research have the potential to shed light on possible new avenues of research. Additional research may prove beneficial on possible synergistic effects of herbs commonly used with S. barbata, such as Hedyotis diffusa and Lobelia chinensis. 


\section{Introduction}

Scutellaria barbata, also known as Ban Zhi Lian or barbat skullcap, is a perennial herb of the Lamiaceae (mint) family that grows on moist flatlands in southeastern China (Fig. 1) (Dharmananda, 2013; Li and Hedge, 2013). Typically harvested in late summer when the plant is in full bloom, the aerial parts of these flowering herbs are dried to use as medicine (Dharmananda, 2013). Traditional Chinese Medicine (TCM) has used S. barbata to treat a spectrum of ailments including hepatitis, appendicitis, pain, pulmonary abscess, ascites due to cirrhosis and cancer (Dharmananda, 2013). However, S. barbata is most noted for its potent anticancer properties and is often combined with other herbs for anticancer TCM formulations to treat cancers of the lung, liver, breast, and gastrointestinal tract (Dharmananda, 2013; Chia, 1985). Western research has recently turned its attention to $S$. barbata as a possible source of anticancer compounds. An aqueous extract of the aerial parts of S. barbata named Bezielle (BZL101) was developed by Bionovo, a California-based biotechnology company, and completed Phase I clinical trials in the United States with favorable results (Rugo et al., 2007; Perez et al., 2010). Unfortunately, the developmental of this $S$. barbata-based medicine has been halted due to insufficient funding (Bionovo, 2015). However, by incorporating knowledge from both Western and TCM perspectives, new directions for further S. barbata research may be discovered. 


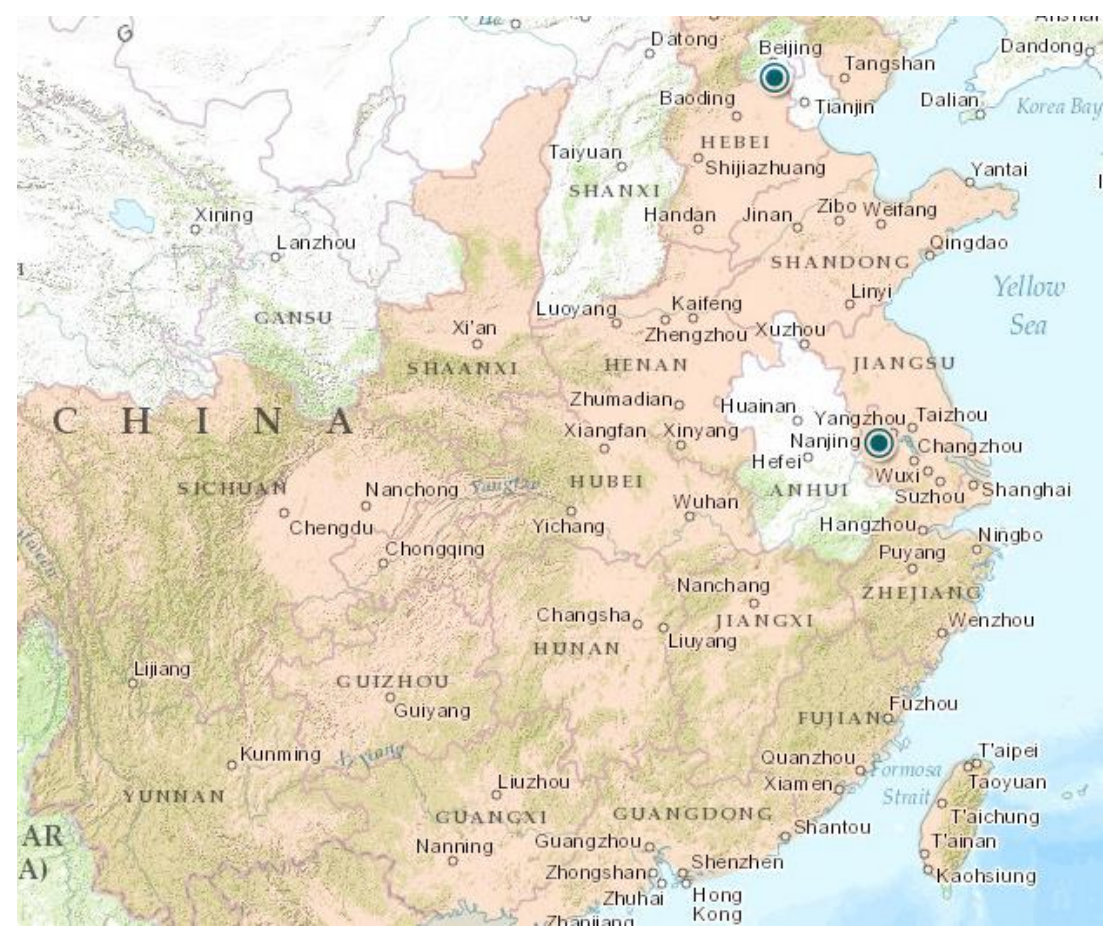

Figure 1 Locations of Beijing and Nanjing in relation to the native habitat of Scutellaria barbata (represented by shaded areas; map created with http://education.nationalgeographic.com/education/mapping/).

Current Western research on the chemistry of $S$. barbata has documented the presence of an array of compounds including flavones and diterpenes with anticancer properties (Wang and Wong, 2011). From BZL101, five active compounds were identified (Fig. 2) (Chen et al., 2012). Among these, flavones such as apigenin and luteolin are well-known to have anticancer activity (Chen et al., 2012; Kim et al. 2005). Chen et al. (2012) found that apigenin exhibited appreciable cytotoxic activity against erythroleukemia (K562), gastric cancer (MGC-803), promyelocytic leukemia (HL60), oral squamous cancer cells (KB) and neuroblastoma (SH-SY5Y). Luteolin was most effective against gastric cancer (MGC-803), promyelocytic leukemia (HL60), and neuroblastoma (SH-SY5Y), liver cancer (SMMC-7221) and colon cancer (SW480) (Kim et al., 2005). However, apigenin and luteolin were reportedly non-selective showing cytotoxicity to 
both human breast cancer cell line MDA-MB-231 as well as non-transformed breast cell line MCF10A (Chen et al, 2012). Another compound from S. barbata with cytotoxicity against MDA-MB-468 breast cancer cells was scutellarein (Androutsopoulos et al., 2009). In addition, scutellarein was determined to be the main component in BZL101 and was the most selective and cytotoxic of the compounds present in this extract. The selectivity of scutellarein was attributed to its ability to induce increasing amount of mitochondrial superoxide, peroxide, and DNA damage while draining cancer cells of ATP by inhibiting glycolysis. Lastly, isoscutellarein was not extensively studied due to weak cytotoxicity, while carthamidin was mentioned to be cytotoxic by generating ROS and DNA damage, but poorly selective. However, it was noted that none of the individual components identified in BZL101 were as cytotoxic as the whole extract, suggesting possible synergistic anticancer activity by the compounds (Chen et al. 2012).<smiles>O=c1cc(-c2ccc(O)cc2)oc2cc(O)cc(O)c12</smiles>

apigenin<smiles>O=C1CC(c2ccc(O)cc2)Oc2cc(O)c(O)c(O)c21</smiles>

carthamidin<smiles>O=c1cc(-c2ccc(O)cc2)oc2c(O)c(O)cc(O)c12</smiles>

isoscutellarein<smiles>O=c1cc(-c2ccc(O)c(O)c2)oc2cc(O)cc(O)c12</smiles>

Iuteolin<smiles>O=c1cc(-c2ccc(O)cc2)oc2cc(O)c(O)c(O)c12</smiles>

scutellarein

Figure 2. Compounds identified from BZL101 (Chen et al., 2012). 
Both in vitro and in vivo testing of $S$. barbata returned promising results for further research. S. barbata has been most extensively studied for breast cancer treatment, with extensive testing done on five different types of breast cancer cells showing S. barbata extracts had more than $50 \%$ inhibition in three out of the five cell lines (Campbell et al., 2002). BZL101 was repeatedly documented to exhibit cytotoxic effects on both ER+ and ER- breast cancer cell lines (Fong et al., 2008; Klawitter et al., 2011; Marconett et al., 2010). Due to strong preclinical data, BZL101 completed Phase Ia and Ib clinical trials for treatment of metastasized breast cancer with encouraging results (Rugo et al., 2007; Perez et al., 2010). Along with its anticancer properties, $S$. barbata has been noted to have anti-inflammatory, anti-complementary, antioxidant, and antimicrobial properties (Chen et al., 2008; Wu and Chen, 2009; Yu et al., 2004; Ye and Huang, 2012). The number and diversity of active components from S. barbata, including alkaloids, flavonoids, tannic acid and essential oils (Dharmananda, 2013) may allow for many kinds of therapeutic potential.

Unlike Western medicine which is typically concerned with quantitative changes on a molecular level, TCM focuses instead on qualitative changes that can be outwardly perceived by the senses. Diagnosis of disease is done using the five senses to identify signs and symptoms which are considered to reflect the status inside the body. In TCM, the body is considered as a whole; disease is believed to be the result of the body becoming imbalanced due to deficiency or excess (Kaptchuk, 2000). To locate the source of imbalance, practitioners take a holistic approach and examine every aspect of the patient's life including mind, body, and environment. Therapy is then individualized based on the specific symptoms of the patient at the time of visit. Physicians will prescribe a unique blend of herbs adjusted to correspond to disease progress. The components of the formula reflect what is needed to bring the body back to balance. 
Due to the fluid nature of TCM formulas, which are often adjusted to correspond to patient symptoms, disease state and constitution, TCM formulas almost always contain many herbs together, sometimes upwards of twenty or more (Yuan et al., 2011; Zhu and Wang, 2011). Herbs may be placed together for the purpose of augmenting effect of individual herbs, treating other symptoms, or minimizing side effects (Zhu and Wang, 2011). This is to take advantage of the synergistic potentiation of therapeutic effect due to multiple herbs that is believed to be greater than the effect of each individual herb. Synergism resulting in maximum therapeutic potential is an important basis of TCM prescribing. Since the whole formula is the unit of therapy, therapeutic effects cannot easily be attributed to any one herb. However, when TCM herbs are studied using Western methodology, their components are commonly isolated and studied individually. Without their original context, the effects of herbs using Western methodology may differ from their traditional TCM efficacy.

This study compares $S$. barbata clinical use by TCM practitioners and current Western research on use of S. barbata. Understanding S. barbata in the context of TCM may help reveal new methods and research directions for further Western research.

\section{Study Area and Methods}

\subsection{Interview structure}

Semi-structured interviews were conducted with TCM practitioners in Nanjing and Beijing, China. A questionnaire regarding clinical therapy using S. barbata was developed to guide each interview (Appendix A). This questionnaire served as a guide with each interview allowed to progress based on practitioner responses. Follow-up questions were asked when appropriate and 
some questions were disregarded as necessary. Both the questionnaire and the interview procedure were approved by University of Connecticut Institutional Review Board (\#H13-111).

Interviews proceeded from May to August 2013 in Beijing and Nanjing, China. Interviews were conducted in Mandarin and all relevant information was provided to interviewees in Mandarin. The interviewer recruited practitioners in person by visiting sites including hospitals, clinics, and independent pharmacies in Beijing and Nanjing. The interviewer asked practitioners if they were willing to answer questions relating to their use of $S$. barbata; willing participants were then recruited for use in this study. Recruitment also involved referrals from personal contacts or from interviewed practitioners. Before each interview, the practitioner was provided with an information sheet, in Mandarin, regarding the purpose of the study, methods incorporated, how information would be used, and how privacy would be protected. After the interviewee reviewed the information sheet, permission was obtained via oral consent.

Interviews generally took place immediately following practitioner consent. Each interview lasted approximately 20-30 minutes, depending on practitioner availability. Focus was primarily on clinical uses of $S$. barbata by each practitioner based on his or her experience. Practitioners were also asked for opinions on various tangential topics including strengths and weaknesses of TCM versus Western medicine, integration of TCM and Western medicine in therapy, and future development of TCM. Each interview was voice recorded for review and translation into English.

\subsection{Statistical methods}

Differences between total number of diseases treated with S. barbata in Beijing and Nanjing were analyzed using the Two-Sample T-Test. Likewise, differences between the total number of herbs used with S. barbata in Beijing and Nanjing were also analyzed. A Fisher's Exact Test was 
used to assess variance between proportions of practitioners who would use $S$. barbata to treat diseases in the two locations as well as to analyze differences between proportions of practitioners in the two cities who would elect to use additional herb(s) in combination with $S$. barbata. Furthermore, Two-Sample Z-Tests were used to examine the difference between frequencies of each herb used with S. barbata.

\subsection{Demographics of practitioners}

As of 2011, just over 420,000 TCM practitioners were reported in China, including TCM doctors, medical assistants, and pharmacists (World Health Organization, 2012). TCM doctors and pharmacists from both hospital and community setting were included in the current study. Five practitioners from Beijing and ten from Nanjing consented to be interviewed. Basic background information regarding practitioners were collected including place of education, degree(s), job title, and years of experience (Table 1). Personal identifiers such as name and place of employment were not recorded in order to protect practitioner privacy. Practitioners were asked to discuss patient cases anonymously to protect patient privacy. Practitioners interviewed for this study were assigned a number and are referred to throughout this paper as P1-P15 when appropriate. 
Table 1

Background of interviewed TCM practitioners

\begin{tabular}{|c|c|c|c|c|c|}
\hline $\begin{array}{l}\text { Practition } \\
\text { er }\end{array}$ & $\begin{array}{l}\text { Locatio } \\
\mathrm{n}\end{array}$ & Educational Background & Degree & Job Title & $\begin{array}{l}\text { Years } \\
\text { Experienc } \\
\text { e }\end{array}$ \\
\hline 1 & Beijing & $\begin{array}{l}\text { Beijing TCM technical secondary } \\
\text { school, } \\
\text { Apprenticeship }\end{array}$ & None & Retail TCM Pharmacist & 28 \\
\hline 2 & Beijing & Beijing TCM University & Ph.D in TCM & $\begin{array}{l}\text { Professor, Part-Time } \\
\text { Clinician }\end{array}$ & 10 \\
\hline 3 & Beijing & $\begin{array}{l}\text { Beijing University of Chinese } \\
\text { Medicine }\end{array}$ & $\mathrm{Ph} . \mathrm{D}$ in $\mathrm{TCM}$ & Attending Physician & 15 \\
\hline 4 & Beijing & $\begin{array}{l}\text { Beijing University of Chinese } \\
\text { Medicine }\end{array}$ & $\begin{array}{l}\text { Masters degree in TCM, } \\
\text { Ph. D Candidate }\end{array}$ & $\begin{array}{l}\text { Attending Physician } \\
\text { Specializing } \\
\text { in Gastroenterology }\end{array}$ & 10 \\
\hline 5 & Beijing & $\begin{array}{l}\text { Beijing University of Chinese } \\
\text { Medicine }\end{array}$ & $\mathrm{Ph} . \mathrm{D}$ in $\mathrm{TCM}$ & Chief Physician & 20 \\
\hline 6 & Nanjing & $\begin{array}{l}\text { Nanjing University of Chinese } \\
\text { Medicine, } \\
\text { Apprenticeship }\end{array}$ & $\begin{array}{l}\text { Bachelors equivalent in } \\
\text { TCM }^{\mathrm{a}}\end{array}$ & Attending Physician & 30 \\
\hline 7 & Nanjing & Nanjing Medical University & $\begin{array}{l}\text { Bachelors equivalent in } \\
\text { TCM }^{\mathrm{a}}\end{array}$ & Chief Physician & 40 \\
\hline 8 & Nanjing & $\begin{array}{l}\text { Nanjing University of Chinese } \\
\text { Medicine }\end{array}$ & Ph.D in TCM & $\begin{array}{l}\text { Professor and Chief } \\
\text { Physician }\end{array}$ & 30 \\
\hline 9 & Nanjing & Nanjing Medical University & Unknown $^{\mathrm{b}}$ & Chief Physician & $\begin{array}{l}\text { Unknown } \\
\text { b }\end{array}$ \\
\hline 10 & Nanjing & $\begin{array}{l}\text { Nanjing University of Chinese } \\
\text { Medicine }\end{array}$ & Masters, Ph.D Candidate & $\begin{array}{l}\text { Chief physician of } \\
\text { Nephrology Department }\end{array}$ & 20 \\
\hline 11 & Nanjing & $\begin{array}{l}\text { Nanjing University of Chinese } \\
\text { Medicine }\end{array}$ & Ph.D in TCM & $\begin{array}{l}\text { Associate Professor, } \\
\text { Chief Physician }\end{array}$ & 30 \\
\hline 12 & Nanjing & $\begin{array}{l}\text { Nanjing University of Chinese } \\
\text { Medicine }\end{array}$ & $\mathrm{Ph} . \mathrm{D}$ in $\mathrm{TCM}$ & $\begin{array}{l}\text { Chief Physician of } \\
\text { Gynecology Department }\end{array}$ & 28 \\
\hline
\end{tabular}


13

$$
\text { Nanjing }
$$

Nantong University Medical College, Southeast University, Nanjing University of Chinese Medicine

14 Nanjing Nanjing University of Chinese Medicine,

Nanjing Medical University

15 Nanjing Nanjing University of Chinese Medicine
Chief Physician of Gynecology Department Ph.D in TCM

Masters in TCM

Masters in TCM
Chief Physician of

Cancer Department

${ }^{a}$ Practitioner was educated before the concept of degrees was widespread in China.

${ }^{\mathrm{b}}$ Data not collected. 


\section{Results}

\subsection{Use of S. barbata in therapy}

S. barbata was used by TCM practitioners to combat a variety of diseases similar to what has previously been recorded in literature (Table 2, Dharmananda, 2013). The most common disease for S. barbata use was cancer with eleven out of fifteen practitioners indicating that they have included S. barbata in treatment of patients with cancer or precancerous conditions (the other four practitioners did not see cancer patients in their practices). In addition, nearly every cancertreating practitioner interviewed indicated they use $S$. barbata to treat over half of their cancer patients. According to Practitioner 5 (P5), cancer is considered a type of toxin in TCM and thus herbs with strong ability to clear toxins such as $S$. barbata are commonly employed. Especially in early or acute stages, P5 indicated, cancer is considered especially toxic and S. barbata is utilized to combat cancer growth. P8 discussed that this herb should only be used in patients who are also exhibiting severe 'heat-pattern' (single quotation will signify TCM definition) symptoms, including dry mouth, bitter taste in mouth, red tongue, and yellow tongue coating. This statement was echoed by almost all practitioners as they stressed that $S$. barbata has extremely 'cold' and 'bitter' properties so should be saved for severe 'heat-toxin' only. P14, who rarely uses $S$. barbata for cancer, indicated that not all cancer patients are appropriate candidates for $S$. barbata treatment the herb may be too 'cold' for weaker cancer patients to handle given that extremely 'cold' herbs may weaken patients further and cause side effects such as poor appetite and gastrointestinal upset. P8 also emphasized that not all cancer patients will present with the same symptoms and uses the herb only when patients have the right symptom profile. P3 prefers $S$. barbata for lung cancer patients because the herb corresponds to the lung meridian and thus P3 believes the therapeutic effect will be potentiated when used to treat lung diseases. No particular 
preference on the type of cancer was reported by other practitioners, with most using S. barbata for an array of cancers.

Other diseases treated using S. barbata by the interviewees included bacterial infections and inflammatory diseases, both associated with 'heat-pattern' issues (Table 2). Use of S. barbata for upper respiratory infections such as bronchitis, pharyngitis, and trachitis was statistically more common in Beijing than in Nanjing $(p<0.05)$. Besides respiratory infections, S. barbata was thought to be effective against skin infections (e.g., acne and cellulitis), urinary tract infections, and pelvic inflammatory disease. Practitioners indicated they use the herb for inflammatory diseases as well, including hepatitis, nephritis, non-acute appendicitis, and ulcerative colitis. Except for their use in upper respiratory infections, practitioners from both cities reported similar diseases treated with $S$. barbata with no significant difference between disease treatment in Beijing and Nanjing. However, several practitioners avoid using S. barbata for infections and inflammatory diseases because as P2 explained that $S$. barbata can be too strong for common upper respiratory infections she usually encounters. P6 indicated he only uses the herb in a few patients with inflammatory diseases saying "there are too many choices for that. There are specific herbs designated to treat certain organ systems." 
Table 2

Diseases or symptoms treated with formulas containing S. barbata. ${ }^{\text {a }}$

\begin{tabular}{|c|c|c|c|c|c|c|c|c|c|c|c|c|c|c|c|c|c|c|}
\hline \multirow[t]{2}{*}{$\begin{array}{l}\text { Disease state or } \\
\text { symptom }\end{array}$} & \multicolumn{5}{|c|}{ Beijing } & \multicolumn{10}{|c|}{ Nanjing } & \multicolumn{3}{|c|}{ General Practitioners ${ }^{g}$} \\
\hline & P1 & P2 & P3 & $\mathbf{P 4 ^ { b }}$ & P5 & P6 & P7 & P8 & P9 & $\mathbf{P 1 0}{ }^{\mathrm{c}}$ & P11 & $\mathbf{P 1 2}^{\mathrm{d}}$ & $\mathbf{P 1 3}^{\text {de }}$ & $\mathrm{P} 4^{\mathrm{e}}$ & P15 & $\begin{array}{c}\text { Beijing } \\
(\mathbf{n}=4)\end{array}$ & $\begin{array}{c}\text { Nanjing } \\
(\mathrm{n}=6)\end{array}$ & $\begin{array}{c}\text { Total } \\
(\mathbf{n}=10)\end{array}$ \\
\hline Cancer & $\mathrm{Y}$ & $\mathrm{Y}$ & $\mathrm{Y}$ & $\mathrm{Y}$ & $\mathrm{Y}$ & $\mathrm{Y}$ & $\mathrm{Y}$ & $\mathrm{Y}$ & $\mathrm{Y}$ & & Y & & & Y & & $\begin{array}{c}4 \\
(100 \%)\end{array}$ & $\begin{array}{c}5 \\
(83.3 \%)\end{array}$ & $\begin{array}{c}9 \\
(90 \%)\end{array}$ \\
\hline Upper respiratory & & & & & & & & & & & & & & & & 4 & 1 & 5 \\
\hline infection & $\mathrm{Y}$ & $\mathrm{Y}$ & $\mathrm{Y}$ & & $\mathrm{Y}$ & $\mathrm{Y}$ & & & & $\mathrm{Y}$ & & & & & & $(100 \%)$ & $(16.7 \%)$ & $(50 \%)$ \\
\hline $\begin{array}{l}\text { Skin infections (acne, } \\
\text { cellulitis, etc.) }\end{array}$ & $\mathrm{Y}$ & $\mathrm{Y}$ & & & $\mathrm{Y}$ & & & $\mathrm{Y}$ & & Y & & & & & Y & $\begin{array}{c}3 \\
(75 \%)\end{array}$ & $\begin{array}{c}2 \\
(33.3 \%)\end{array}$ & $\begin{array}{c}5 \\
(50 \%)\end{array}$ \\
\hline & & & & & & & & & & & & & & & & 1 & 2 & 3 \\
\hline Abscess & & $\mathrm{Y}$ & & & & $\mathrm{Y}$ & $\mathrm{Y}$ & & & $\mathrm{Y}$ & & & & & & $(25 \%)$ & $(33.3 \%)$ & $(30 \%)$ \\
\hline & & & & & & & & & & & & & & & & 1 & 1 & 2 \\
\hline Bug and snake bites & & $\mathrm{Y}$ & & & & $\mathrm{Y}$ & & & & $\mathrm{Y}$ & & & & & & $(25 \%)$ & $(16.7 \%)$ & $(20 \%)$ \\
\hline Swelling & & & & & & & & Y & & $\mathrm{Y}$ & & & & & Y & $\begin{array}{c}0 \\
(0 \%)\end{array}$ & $\begin{array}{c}2 \\
(33.3 \%)\end{array}$ & $\begin{array}{c}2 \\
(20 \%)\end{array}$ \\
\hline Fluid accumulation & & & & & & & & & & & & & & & & 0 & $\begin{array}{c}(30.510) \\
1\end{array}$ & 1 \\
\hline (edema, ascites) & & & & & & & $\mathrm{Y}$ & & & Y & & & & & & $(0 \%)$ & $(16.7 \%)$ & $(10 \%)$ \\
\hline Redness due to & & & & & & & & & & & & & & & & 1 & 1 & 2 \\
\hline inflammation & $\mathrm{Y}$ & & & & & & & & & & & & & & $\mathrm{Y}$ & $(25 \%)$ & $(16.7 \%)$ & $(20 \%)$ \\
\hline & & & & & & & & & & & & & & & & 1 & 0 & 1 \\
\hline External injuries & & & & & $\mathrm{Y}$ & & & & & $\mathrm{Y}$ & & & & & & $(25 \%)$ & $(0 \%)$ & $(10 \%)$ \\
\hline Henatitis & & & & & & $\mathrm{Y}$ & & $\mathrm{y}$ & & & & & & & & $\begin{array}{c}0 \\
0 \%\end{array}$ & $\begin{array}{c}2 \\
(33307\end{array}$ & $\begin{array}{c}2 \\
(20 \%)\end{array}$ \\
\hline пераatus & & & & & & 1 & & 1 & & & & & & & & 0 & $\begin{array}{c}(35.5 \%) \\
0\end{array}$ & $\begin{array}{c}(20 \%) \\
0\end{array}$ \\
\hline Atrophic gastritis & & & & $\mathrm{Y}$ & & & & & & & & & & & & $(0 \%)$ & $(0 \%)$ & $(0 \%)$ \\
\hline & & & & & & & & & & & & & & & & 0 & 0 & 0 \\
\hline Ulcerative colitis & & & & $\mathrm{Y}$ & & & & & & & & & & & & $(0 \%)$ & $(0 \%)$ & $(0 \%)$ \\
\hline & & & & & & & & & & & & & & & & 1 & 0 & 1 \\
\hline Appendicitis & & & & & $\mathrm{Y}$ & & & & & & & & & & & $(25 \%)$ & $(0 \%)$ & $(10 \%)$ \\
\hline & & & & & & & & & & & & & & & & 0 & 1 & 1 \\
\hline Liver cirrhosis & & & & & & & & & & & Y & & & & & $(0 \%)$ & $(16.7 \%)$ & $(10 \%)$ \\
\hline & & & & & & & & & & & & & & & & 0 & 1 & 1 \\
\hline Nephritis & & & & & & $\mathrm{Y}$ & & & & & & & & & & $(0 \%)$ & $(16.7 \%)$ & $(10 \%)$ \\
\hline Urinary Tract & & & & & & & & & & & & & & & & 0 & 0 & 0 \\
\hline Infection & & & & & & & & & & $\mathrm{Y}$ & & & & & & $(0 \%)$ & $(0 \%)$ & $(0 \%)$ \\
\hline
\end{tabular}


Pelvic inflammatory

disease

Bacterial Pneumonia

Jaundice

\section{Y}

\section{Y}

Y

Bleeding/Bruising

${ }^{a}$ Practitioners reported either using these herbs themselves or mentioned the possibility of using these herbs in a formula with $S$. barbata

${ }^{b}$ Specialist in Gastroenterology.

c Specialist in Nephrology.

d Specialists in Gynecology.

e This practitioner is not actively practicing TCM but has the credentials to do so.

${ }^{\mathrm{f}}$ Specialist in Oncology.

g Excludes specialist practitioners P4, P10, P12, P13, P14.
$0 \quad 0 \quad 0$

$(0 \%) \quad(0 \%) \quad(0 \%)$

$1-0 \quad 1$

(25\%) $\quad(0 \%) \quad(10 \%)$

$0 \quad 0 \quad-0$

$(0 \%) \quad(0 \%) \quad(0 \%)$

$1 \quad 0 \quad 1$

$(0 \%) \quad(10 \%)$ 
Several practitioners indicated that $S$. barbata can cause diuresis, which may be used to reduce swelling, abscess, or fluid accumulation as symptoms of other diseases (P2, P6, P7, P8, P10). S. barbata also was reported to cause slight hemostasis and thus, in addition to its antimicrobial properties, was considered a good choice for bug and snake bites as well as treating external cuts using juices of fresh herbs (P2, P6, P10). Lastly, the herb is thought to promote blood circulation, which may improve liver cirrhosis and bruises (P5, P11). Other than internal uses, P15 also prescribes S. barbata as a foot soak for patients with swelling, infections, and inflammation in the lower extremities. Overall, S. barbata was considered only for treatment of disease, although two practitioners (P1 and P5) expressed that it may be possible for preventative use as well. P5 indicated that $S$. barbata was not typically used for prevention because the properties may be too strong and several other practitioners would not recommend the herb for preventative use (P2, P3, P8, P14).

The common dose range for S. barbata in cancer patients was reported by practitioners as 1030 grams of raw herb daily. Practitioners prescribed lower dosages when patients present with poor constitution or less severe 'heat-pattern' symptoms, with higher doses used if the practitioner deemed the patient strong enough. The highest reported dose for $S$. barbata for cancer was 50 grams (P1). For infections, the dose was generally less than cancer at around 1020 grams (P2, P5, P6, P12), although P10 reported that he uses up to 30 grams for his patients with UTI. Likewise, 30 grams or more was reported by P15 but he uses it externally to treat swelling and skin infections where he indicated that dose is less important since the herb is not taken internally.

\subsection{S. barbata with other herbs in therapy}


Traditional Chinese Medicine emphasizes using formulas for a multi-target approach to treating diseases (P8). The TCM practitioners interviewed herein repeatedly discussed that therapeutic and adverse effects can only be credited to the formula and not to an individual herb. Numerous herbs have been combined with $S$. barbata (Table 3), with the most commonly paired herb, Hedyotis diffusa, used significantly more often than the second most paired herb, Lobelia chinensis $(p<0.05)$. Out of fifteen practitioners, ten mentioned either having prescribed $H$. diffusa and S. barbata together for cancer treatment or, if they do not see cancer patients themselves, recognized the possibility of using $H$. diffusa with $S$. barbata. Both herbs have similar properties, exhibiting 'cold' and 'bitter' properties. P1 stated that the two herbs are often used together to augment the other's effects, an opinion echoed by other practitioners who also use the two herbs together (P7, P9, P11). P14 preferred $H$. diffusa over $S$. barbata because $H$. diffusa has been noted by Western research to improve functioning of the immune system (e.g., Yoshida et al., 1997).

The next most commonly paired herb was Lobelia chinensis (Table 3) and like H. diffusa, L. chinensis was reported to have similar 'cold' and 'bitter' properties and thus was combined with S. barbata to strengthen the effect of both herbs (P1, P8). P11 suggested that when S. barbata is used with $L$. Chinensis, there would be a reduction in cancer symptoms such as pain.

Though $H$. diffusa and L. chinensis are thought to augment the anticancer effects of $S$. barbata, introducing excessive 'cold' herbs may cause side effects. Astragalus mongholicus, Zingiber officinale (ginger), Coptis chinensis, Adenophora stricta, and Codonopsis pilosula were reported by practitioners as examples of herbs that are 'warm' in property and are thus added to the $S$. barbata formula to prevent damage to the 'spleen' (functionally defined as the system that extracts Qi from food and distributes it to the rest of the body and thus does not correspond to the 
anatomical organ) (Zhu and Wang, 2011). However, 'hot' herbs like ginseng which are on the opposite extreme of cold herbs were not reported to be used (P2).

Along with anticancer herbs, TCM practitioners will often add additional herbs to strengthen the body's defense against disease (Yuan et al., 2011). Practitioners cited that cancer patients often lack Qi, Yin, and 'blood' (system that transports nourishment throughout the body) (P3, P5, P9) and thus practitioners reported to add herbs that strengthen elements patients lack. P3 reported very little use of $S$. barbata in formulas, instead focusing on strengthening the patient since cancer patients may often be too weak to handle strong anticancer herbs. In a comparison of practitioners from Beijing and Nanjing, there was no significant difference in the choice or frequency of use of herbs paired with S. barbata $(p>0.10)$. 
Table 3

Other herbs used in formulas with S. barbata. $^{\text {a }}$

\begin{tabular}{|c|c|c|c|c|c|c|c|c|c|c|c|c|c|c|c|c|c|c|}
\hline \multirow[t]{2}{*}{ Scientific name (Herb name in pinyin) } & \multicolumn{5}{|c|}{ Beijing } & \multicolumn{10}{|c|}{ Nanjing } & \multicolumn{3}{|c|}{ General Practitioners $^{\mathrm{g}}$} \\
\hline & P1 & P2 & P3 & $\mathbf{P 4 ^ { b }}$ & P5 & P6 & P7 & P8 & P9 & $\mathbf{P 1 0 ^ { c }}$ & P11 & $\mathbf{P} 12^{\mathrm{d}}$ & $\mathbf{P 1 3}^{\text {de }}$ & $\mathrm{P}^{14^{\mathrm{f}}}$ & P15 & $\begin{array}{c}\text { Beijing } \\
(\mathbf{n}=4)\end{array}$ & $\begin{array}{c}\text { Nanjing } \\
(\mathrm{n}=6)\end{array}$ & $\begin{array}{c}\text { Total } \\
(\mathbf{n}=10)\end{array}$ \\
\hline Hedyotis diffusa (baihuasheshecao) & $\mathrm{Y}$ & $\mathrm{Y}$ & & Y & $\mathrm{Y}$ & $\mathrm{Y}$ & $\mathrm{Y}$ & & $\mathrm{Y}$ & & Y & Y & & $\mathrm{Y}$ & & $\begin{array}{c}3 \\
(75 \%)\end{array}$ & $\begin{array}{c}4 \\
(66.7 \%)\end{array}$ & $\begin{array}{c}7 \\
(70 \%)\end{array}$ \\
\hline Lobelia chinensis (banbianlian) & $\mathrm{Y}$ & & $\mathrm{Y}$ & & & & & $\mathrm{Y}$ & & & Y & & & & & $\begin{array}{c}(50 \%) \\
1\end{array}$ & $\begin{array}{c}(33.3 \%) \\
1\end{array}$ & $\begin{array}{c}(40 \%) \\
2\end{array}$ \\
\hline Astragalus mongholicus (huanqi) & & & $\mathrm{Y}$ & $\mathrm{Y}$ & & & & & $\mathrm{Y}$ & & & & & & & $\begin{array}{c}(25 \%) \\
1\end{array}$ & $\begin{array}{c}(16.7 \%) \\
0\end{array}$ & $\begin{array}{c}(20 \%) \\
1\end{array}$ \\
\hline Zingiber officinale (shengjiang) & & $\mathrm{Y}$ & & $\mathrm{Y}$ & & & & & & & & & & & & $\begin{array}{c}(25 \%) \\
1\end{array}$ & $\begin{array}{c}(0 \%) \\
0\end{array}$ & $\begin{array}{c}(10 \%) \\
1\end{array}$ \\
\hline Coptis chinensis (huanlian) & & $\mathrm{Y}$ & & $\mathrm{Y}$ & & & & & & & & & & & & $\begin{array}{c}(25 \%) \\
2\end{array}$ & $\begin{array}{c}(0 \%) \\
0\end{array}$ & $\begin{array}{c}(10 \%) \\
2\end{array}$ \\
\hline Adenophora stricta (shashen) & & & $\mathrm{Y}$ & & $\mathrm{Y}$ & & & & & & & & & & & $\begin{array}{c}(50 \%) \\
0\end{array}$ & $\begin{array}{c}(0 \%) \\
1\end{array}$ & $\begin{array}{c}(20 \%) \\
1\end{array}$ \\
\hline Glycyrrhiza uralensis (gancao) & & & & $\mathrm{Y}$ & & & & & $\mathrm{Y}$ & & & & & & & $\begin{array}{c}(0 \%) \\
0\end{array}$ & $\begin{array}{c}(16.7 \%) \\
2\end{array}$ & $\begin{array}{c}(10 \%) \\
2\end{array}$ \\
\hline Codonopsis pilosula (dangshen) & & & & & & & & & $\mathrm{Y}$ & & Y & & & & & $\begin{array}{c}(0 \%) \\
0\end{array}$ & $\begin{array}{c}(33.3 \%) \\
2\end{array}$ & $\begin{array}{c}(20 \%) \\
2\end{array}$ \\
\hline Carthamus tinctorius (honghua) & & & & & & & & & & & Y & & & & $\mathrm{Y}$ & $\begin{array}{c}(0 \%) \\
0\end{array}$ & $\begin{array}{c}(33.3 \%) \\
2\end{array}$ & $\begin{array}{c}(20 \%) \\
2\end{array}$ \\
\hline Angelica sinensis (danggui) & & & & & & & & & & & Y & & & & $\mathrm{Y}$ & $\begin{array}{c}(0 \%) \\
1\end{array}$ & $\begin{array}{c}(33.3 \%) \\
0\end{array}$ & $\begin{array}{c}(20 \%) \\
1\end{array}$ \\
\hline Cordyline fruticosa (Leaf) (tieshuye) & $\mathrm{Y}$ & & & & & & & & & & & & & & & $\begin{array}{c}(20 \%) \\
1\end{array}$ & $\begin{array}{c}(0 \%) \\
0\end{array}$ & $\begin{array}{c}(10 \%) \\
1\end{array}$ \\
\hline Ophiopogon japonicus (maidong) & & & $\mathrm{Y}$ & & & & & & & & & & & & & $\begin{array}{c}(20 \%) \\
0\end{array}$ & $\begin{array}{c}(0 \%) \\
0\end{array}$ & $(10 \%)$ \\
\hline Pinellia ternata (banxia) & & & & $\mathrm{Y}$ & & & & & & & & & & & & $\begin{array}{c}(0 \%) \\
1\end{array}$ & $\begin{array}{c}(0 \%) \\
0\end{array}$ & $\begin{array}{c}0(0 \%) \\
1\end{array}$ \\
\hline Chrysanthemum sp. (juhua) & & & & & $\mathrm{Y}$ & & & & & & & & & & & $\begin{array}{c}(20 \%) \\
1\end{array}$ & $\begin{array}{c}(0 \%) \\
0\end{array}$ & $\begin{array}{c}(10 \%) \\
1\end{array}$ \\
\hline Mentha sp. (bohe) & & & & & $\mathrm{Y}$ & & & & & & & & & & & $\begin{array}{c}(20 \%) \\
0\end{array}$ & $\begin{array}{c}(0 \%) \\
1\end{array}$ & $\begin{array}{c}(10 \%) \\
1\end{array}$ \\
\hline Ranunculi ternati (root) (maozhuacao) & & & & & & $\mathrm{Y}$ & & & & & & & & & & $(0 \%)$ & $(16.7 \%)$ & $(10 \%)$ \\
\hline Paris polyphylla (chonglou) & & & & & & & $\mathrm{Y}$ & & & & & & & & & 0 & 1 & 1 \\
\hline
\end{tabular}


Rhiizoma dioscoreae from Henan of

China (huaishanyao)

Atractylodes macrocephala koidz

(baizhu)

Coix lacryma-jobi (yiyi)

Saussurea costus (yunmuxiang)

Viola philippica (zihuadiding)

Centella asiatica (jixuecao)

Curcuma zedoaria (eshu)

Pseudobulbus cremastrae seu pleiones

(shancigu)

Houttuynia cordata (yuxingcao)

Panax pseudoginseng (sanqi)

Bupleurum chinense (chaihu)

Agrimonia eupatoria (xianhecao)

Ligusticum chuanxiong hort

(chuanxiong)

\begin{tabular}{|c|c|c|c|}
\hline & $(0 \%)$ & $(16.7 \%)$ & $(10 \%)$ \\
\hline & 0 & 1 & 1 \\
\hline & $(0 \%)$ & $(16.7 \%)$ & $(10 \%)$ \\
\hline & 0 & 1 & 1 \\
\hline & $(0 \%)$ & $(16.7 \%)$ & $(10 \%)$ \\
\hline & 0 & 1 & 1 \\
\hline & $(0 \%)$ & $(16.7 \%)$ & $(10 \%)$ \\
\hline & 0 & 1 & 1 \\
\hline & $(0 \%)$ & $(16.7 \%)$ & $(10 \%)$ \\
\hline & 0 & 0 & 0 \\
\hline & $(0 \%)$ & $(0 \%)$ & $(0 \%)$ \\
\hline & 0 & 0 & 0 \\
\hline & $(0 \%)$ & $(0 \%)$ & $(0 \%)$ \\
\hline & 0 & 0 & 0 \\
\hline & $(0 \%)$ & $(0 \%)$ & $(0 \%)$ \\
\hline & 0 & 1 & 1 \\
\hline & $(0 \%)$ & $(16.7 \%)$ & $(10 \%)$ \\
\hline & 0 & 1 & 1 \\
\hline & $(0 \%)$ & $(16.7 \%)$ & $(10 \%)$ \\
\hline & 0 & 1 & 1 \\
\hline & $(0 \%)$ & $(16.7 \%)$ & $(10 \%)$ \\
\hline & 0 & 1 & 1 \\
\hline & $(0 \%)$ & $(16.7 \%)$ & $(10 \%)$ \\
\hline & 0 & 1 & 1 \\
\hline & $(0 \%)$ & $(16.7 \%)$ & $(10 \%)$ \\
\hline & 0 & 0 & 0 \\
\hline $\mathrm{Y}$ & $(0 \%)$ & $(0 \%)$ & $(0 \%)$ \\
\hline & 0 & 1 & 1 \\
\hline Y & $(0 \%)$ & $(16.7 \%)$ & $(10 \%)$ \\
\hline
\end{tabular}

${ }^{\text {a }}$ Practitioners reported either using these herbs themselves or mentioned the possibility of using these herbs in a formula with $S$. barbata.

b Specialist in Gastroenterology.

${ }^{c}$ Specialist in Nephrology.

d Specialists in Gynecology.

e This practitioner is not actively practicing TCM but has the credentials to do so.

${ }^{\mathrm{f}}$ Specialist in Oncology.

${ }^{\mathrm{g}}$ Excludes specialist practitioners P4, P10, P12, P13, P14. 


\subsection{S. barbata and adverse events}

S. barbata is considered a strongly 'cold' and 'bitter' herb in TCM. Several practitioners reported that 'cold' and 'bitter' herbs generally damage the 'spleen' which causes negative effects on the GI tract like diarrhea, poor appetite, and GI upset (P1, P2, P3, P5, P10, P12). When dealing with the side effects of this herb, most practitioners will add 'warm' herbs into the formula to minimize the effect of the 'cold' herb. P4 reported recommending ginger tea to patients experiencing adverse effects from the herb. P2 indicated that taking the formula around an hour after meals can reduce GI effects. Dose reducing should also be considered; it may be that the dose is too high for the patient to tolerate. Like Western medicine, the higher the dose of the herb, the more side effects. P4 cited that this is one reason TCM practitioners generally use formulas and no single herb treatments, indicating that "we use other herbs so the different properties can minimize side effects to as low as possible while allowing the therapeutic effect to reach its maximum." P8 discussed that he considers most of the undesirable effects seen from TCM formulas are due to misuse of herbs, such as using an herb when no corresponding symptom is observed or failure to diagnose another underlying condition. "The patient may not just have severe 'interior heat' but also weak in 'spleen'; if you use Scutellaria barbata here there may be GI side effects. Would you say this is a side effect of the herb or misuse?" (P8).

In TCM philosophy, strong herbs are efficacious but also toxic on the body. TCM practitioners interviewed herein consider $S$. barbata as such and may take a break from using this herb partway through the therapeutic regimen. P9 will give a formula containing $S$. barbata to patients for one month and then take a break for one month. During the break, P9 will only give herbs that add Qi and 'blood' to support the body's own defense. P11 chooses to reduce the 
amount or extend the time between doses for patients taking $S$. barbata for more than half a year. P3 will stop using S. barbata for patients experiencing GI problems or other temporary illnesses until the patient is better. For inflammatory or infectious diseases, S. barbata is usually taken until there are no more symptoms (P8, P10, P15). Exceptions are chronic inflammatory diseases like Chronic Pelvic Inflammatory Disease which requires longer therapeutic period. P12 reported in these cases a one week break after three weeks of treatment is preferred, usually during menses. Most practitioners agreed that $S$. barbata should not be taken long-term. P10 indicated that taking this herb continuously will negatively affect appetite and impact the digestive system and may disturb the balance in the body's Yin and Yang. However, such caution only applies when this herb is used internally with P15 reported $S$. barbata is safe for long-term treatment externally as long as the patient does not exhibit symptoms of allergy.

Drug interaction is always a concern when multiple drugs are used together, though all practitioners who were asked expressed no serious apprehension regarding drug interaction of $S$. barbata with Western medicine or other TCM herbs. P1 suggested it is generally a good idea to space TCM and Western medicine by at least two hours but cited no specific problems. P5 and P7 cited old TCM teaching called the "Eighteen Incompatible Medicaments and Nineteen Counteractions" which lists herbs that cannot go with each other in TCM. Both reported $S$. barbata is not listed in there but warned that the old teaching may not be strictly true now although they personally have not seen any sort of interaction.

According to all practitioners, a broad patient population can be prescribed S. barbata. Since TCM theory applies specific symptoms to specific herbs, most people with the appropriate symptoms can use the herb. Age is also not a limiting factor though dosing may be adjusted according to weight (P5). The consensus among practitioners was that patients with a weak 
constitution or excessive 'cold' in body should not use this herb or use this herb sparingly and combine with other herbs that cancel out its 'cold' property. Patients with chronic GI problems should not use $S$. barbata or use small amounts since 'cold' herbs in general cause GI discomforts (P1, P3, P9). All practitioners will not use this herb in pregnant patients.

\subsection{Future development of S. barbata}

Out of nine practitioners who were asked about their knowledge of S. barbata's mechanism of action on a cellular level, none knew any specifics. Only P2, P7 and P12 indicated that they have read research that $S$. barbata contains anticancer and antimicrobial components. In general, TCM practitioners show less interest in knowing the components and mechanism of action of herbs they use. P7 explained "TCM is different from Western medicine in that TCM looks at what symptoms patients are experiencing and use herbs that correspond to the symptoms. That means as a TCM doctor I can use this herb as long as it is within TCM logics." P7 clarified that TCM philosophy does not rely on knowing the herb's microscopic details; therefore, "I don't feel the need to understand all the components in this herb or make sure this herb has scientifically proven anticancer properties before using it." Though TCM doctors do not need research evidence to use an herb, P12 reported that because current research has found anticancer components, some TCM doctors elect to use S. barbata in their formulas. P4 cited a lack of time, saying they only can understand the components of the few commonly used herbs. Out of the

seven who had not heard of research on S. barbata, most theorized correctly that the field of cancer research is most popular for this herb. P1 did not think S. barbata research is a worthwhile investment due to the low cost and wide availability of the herb. P12 also noted that many times research confirms what TCM practitioners have observed from clinical experience 
without offering new clinically valuable information. For example, current research has shown an antimicrobial effect for S. barbata, which TCM doctors have long used for treating infections (Chen et al., 2008; Wu and Chen 2009; Yu et al. 2004, Ye and Huang 2012). Overall, many practitioners support the research of TCM herbs in the West, citing superior technology to better isolate active components in the herb. Practitioners also think research on herbal medicine would help to provide better standardization in the West, given that quality control is an issue in China.

\section{Discussion}

\subsection{Comparison of current $\mathrm{S}$. barbata research with traditional TCM uses}

Compared to traditional use of $S$. barbata by TCM practitioners, Western research has followed a similar direction but with key differences in both clinical and laboratory studies. Although Western research often confirms TCM observations, there are instances where results differ. S. barbata has been shown to be effective against a variety of cancer cell lines in vitro which agrees with TCM use of the herb on a range of different cancers. However, increased efficacy against lung cancers was noted by P3 because $S$. barbata is thought to have affinity for the lung meridian. Several recent laboratory studies on lung cancer have identified notable anticancer effects on a variety of lung cancer cell lines (Yang et al., 2015; Shiau et al., 2014; Yang et al., 2014; Gong et al., 2015). One Western study noted that S. barbata extract had greater than 50\% inhibition for human lung carcinoma (A549), but also found that S. barbata was more effective against human breast adenocarcinoma (MCF-7) (Shoemaker et al., 2005). However, it is important to note that TCM meridian channels are defined in human bodies and no Western clinical research has been performed using $S$. barbata in lung cancer patients. 
In areas outside of cancer, $S$. barbata is used by TCM practitioners to treat inflammation and infections (Ye and Huang 2012). A flavone from S. barbata, wogonin, in particular was shown to have anti-inflammatory effects by inhibiting PMA-induced K-Jun protein responsible for enhancing COX-2 expression (Chen et al. 2008). Essential oil from S. barbata was also noted to be bactericidal against Gram positive bacteria (Yu et al., 2004). Another study reported flavones from S. barbata (e.g., apigenin and luteolin) were effective against both methicillin sensitive and resistant strains of Staphylococcus aureus (Sato et al., 2000). One potential indication found in Western research that has not been reported by TCM practitioners involves the effect of $S$. barbata on the complement cascade, introducing the possibility of use for diseases such as rheumatoid arthritis and Alzheimer's (Wu and Chen, 2009). Conversely, TCM practitioners reported using S. barbata for fluid accumulation (e.g., ascites) or as a topical therapeutic but no reports for these indications have been found in the Western literature.

\subsection{Comparison of S. barbata clinical trials with traditional TCM uses}

Through possible TCM indications are diverse, preparation of $S$. barbata for ingestion is typically performed using similar techniques. The traditional method of extracting TCM herbs by simmering in water was followed when making extracts of $S$. barbata for both Ia and Ib phases of BZL101's clinical trials (Rugo et al., 2007; Perez et al., 2010). However, during Phase Ib, a modified formulation using freeze-dried powdered drug with sweeteners and taste-masking excipients was introduced to increase patient adherence. It is unclear if freeze-drying or the addition of other excipients would change efficacy but neither are traditionally used by TCM practitioners. However, one major benefit of the modernization of dosage form involves increased patient compliance since it was noted that during Phase Ia trials some patients 
discontinued therapy due to bitter taste of the drug when prepared using traditional methods (Rugo et al., 2007). In the Phase Ib trial, after implementing the new dosage form, patient compliance increased and no patients dropped out of study due to drug taste (Perez et al., 2010).

Poor patient compliance due to lack of drug palatability was reported to be a common issue for TCM practitioners. Due to bitter taste, long time to effect, and inconvenience in preparing a TCM concoction, many patients may not adhere to the treatment regimen long enough to see an effect (P12). Though a move to premade dosage forms may limit the TCM practice of individualizing medicines, most practitioners supported this type of dosage modification since some patients will not take the traditional tea and are thus not receiving any therapeutic effect.

Since TCM regimens tend to be lengthy for full effect, TCM practitioners frequently have their patients take a break in therapy, discontinuing the use of $S$. barbata and other anticancer herbs due to their toxicity on the body (P9). Contrary to this practice, the two clinical trials of BZL101 involved daily dosing that was only discontinued due to patient preference, intolerable side effects, or progression of disease (Rugo et al., 2007; Perez et al., 2009). The longest continued use of $S$. barbata was 449 days by one patient during the Phase Ib trial (Perez et al., 2010). The TCM medical philosophy dictates that prolonged exposure to 'cold' herbs may negatively affect patient health. Using excessively 'cold' herbs for a prolonged period, P10 cautioned, disturbs the digestive system and may imbalance the Yin and Yang in the body. To prevent this, P9 stops $S$. barbata every other month and instead give his patients different herbs to improve body constitution, while P11 either reduces the dose of $S$. barbata or extends the time between doses after six months of continuous treatment. Treatment breaks could be considered by during clinical trials of $S$. barbata and other 'cold' herbs to minimize harm, decreasing negative side effects and thus increasing willingness to stay on treatment. 
In TCM another way to minimize adverse events and maximize therapeutic efficacy involves the use of the right combination of herbs. Choosing herbs that correspond to individual patient symptoms is a key facet of TCM prescribing. All fifteen TCM practitioners emphasize that 'heat' symptoms must be present in order to use $S$. barbata. Both Phase Ia and Ib clinical trials of $S$. barbata involved patients with metastatic breast cancer without noting other initial symptoms of patients, although patient overall health was graded using the Karnofsky performance score with an inclusion criteria of $80 \%$ need to participate in the trials (Rugo et al., 2007; Perez et al., 2010). TCM practitioners would likely have deemed these patients well enough to receive a 'cold' herb like S. barbata, but in TCM the overall constitution of the patient is not the only criteria for using an herb, as cancer manifests in all kinds of patterns of symptoms (P8). "It's hard to say even for one patient. As cancer develops, the patient's symptoms may change so sometimes you can use Scutellaria barbata and other times you cannot" (P8). Given all of the other symptoms that are taken into account by TCM practitioners, it is possible that the efficacy of $S$. barbata and the side effect profile may differ from its use in Western research.

Another issue with efficacy and side effect profiles involves dose. Almost all the interviewed TCM practitioners (with the exception of P8, P13, and P14) recommend a dose range between 10-30g/day of raw herb $S$. barbata though this amount varies depending on patient symptoms, constitution, and size of the formula. In the Phase Ib trial of BZL101, the highest dose used was 40g/day of dried extract (Perez et al., 2010). According to the published preparation method, BZL101 was prepared using $180 \mathrm{~g}$ of raw herb resulting in approximately $10 \mathrm{~g}$ of dry extract (Rugo et al., 2007) and thus the dosage of 40g/day of dried extract might be substantially higher than doses given by TCM practitioners. Many TCM practitioners warn that a large amount of 'cold' herbs may lead to side effects such as GI distress (P1, P2, P3, P4, P6, P9, P10, P12), 
which corresponds to the main side effect noted during both Phase Ia and Ib clinical trials (Rugo et al., 2007; Perez et al., 2010).

The use of multi-component formulas as in TCM has the potential to also lead to increased efficacy. P8 discussed that TCM practitioners almost always use formulas because they have clinically observed better efficacy and reduced side effects than when using single herbs. A similar phenomenon was observed with the in vitro research of $S$. barbata in which the highest cytotoxic activity of BZL101 was demonstrated when testing the whole extract rather than purified components from the extract (Perez et al., 2010). It was hypothesized that the anticancer activity of $S$. barbata components may be synergistic, ultimately resulting in a cumulative activity more effective than any isolated component at the same dose (Perez et al., 2010). This finding introduces a possible new direction for future $S$. barbata research, studying the efficacy when combined with herbs commonly paired in TCM formulations such as $H$. diffusa or $L$. chinensis. There may be components in these two herbs that lead to additive and/or synergistic anticancer activity and thus it may be possible for future development of multicomponent preparations.

\section{Conclusion}

This study examined the original context of $S$. barbata use through interviews with TCM practitioners on their clinical use and compared this to the use of the herb in Western research. Although some similarities were noted in the application of S. barbata to treatment of cancer, there were notable differences including the use of the herb by TCM practitioners for respiratory infections and inflammation. Dosing regimen and length of therapy were also found to vary between TCM practitioners and Western studies, and may be important factors in the frequency 
of adverse events. Side effects may be further reduced by taking into account initial patient symptoms as in TCM, along with the addition of other herbs specifically to cancel out side effects. An interesting finding from these comparisons was improvement in patient adherence during the BZL101 clinical trials after altering the dosage form via sweeteners and taste-masking agents that are not part of the traditional preparation.

While our study was limited to a small sample of TCM practitioners, the results found here can be utilized to consider the most appropriate avenues for future research on $S$. barbata. Consulting with longstanding wisdom held by TCM practitioners may provide insight into new directions for traditional medicine research on $S$. barbata. The similarities and differences in diagnosis and treatment regimens between the TCM practitioners and Western research shed light on possible new research. For example, additional research may be warranted on the possible synergistic effects of herbs commonly used with S. barbata, such as Hedyotis diffusa and Lobelia chinensis. In fact, a recent population based study in Taiwan showed that a combination of $S$. barbata and $H$. diffusa is the most commonly used herbal preparation to treat breast cancer in Taiwan; researchers of the study also concluded that there is potential clinical activity of these two herbs when combined warranting further clinical trials (Yeh et. al 2014). It may prove beneficial for future research to address a combination of herbs with $S$. barbata to maximize therapeutic benefit.

\section{Acknowledgements}

The authors acknowledge their gratitude to interviewed practitioners from both Beijing and Nanjing. Statistical analysis support was provided by Brian Bader at the University of 
Connecticut Department of Statistics. Travel expenses funded in part by John and Valerie Rowe Health Professions Scholars Program.

*This thesis was published in the Journal of Ethnopharmacology in February 2016. Tao, G.; Balunas, M.J. Current therapeutic role and medicinal potential of Scutellaria barbata in Traditional Chinese Medicine and Western research. J. Ethnopharmacol. 2016, 182, 170-180. 


\section{References}

Androutsopoulos, V. P.; Ruparelia, K.; Arroo, R. R.; Tsatsakis, A. M.; Spandidos, D. A., 2010. CYP1-mediated antiproliferative activity of dietary flavonoids in MDA-MB-468 breast cancer cells. Toxicol. 264, 162-170.

Bionovo. Bionovo Restructures Work Force Management Compensation Restructured. Available at: http://bionovo.com/investors/pr/MjAxMjAzMDkyMDAw. Accessed April 1, 2015.

Campbell, M.J., Hamilton, B., Shoemaker, M., Tagliaferri, M., Cohen, I., Tripathy, D., 2002. Antiproliferative activity of Chinese medicinal herbs on breast cancer cells in vitro. Anticancer Res. 22, 3843-3852.

Chen, L. G.; Hung, L. Y.; Tsai, K. W.; Pan, Y. S.; Tsai, Y. D.; Li, Y. Z.; Liu, Y. W., 2008. Wogonin, a bioactive flavonoid in herbal tea, inhibits inflammatory cyclooxygenase- 2 gene expression in human lung epithelial cancer cells. Mol. Nutr. Food Res. 52, 1349-1357.

Chen, V.; Staub, R. E.; Baggett, S.; Chimmani, R.; Tagliaferri, M.; Cohen, I.; Shtivelman, E., 2012. Identification and analysis of the active phytochemicals from the anti-cancer botanical extract Bezielle. PLoS One 7, e30107.

Chia, K., 1985. Prevention and treatment of carcinoma in traditional Chinese medicine. Commercial Press, Hong Kong.

Dharmananda, S., 2004. Institute for Traditional Medicine and Preventive Health Care. Oldenlandia and Scutellaria: antitoxin and anticancer herbs. Available at: http://www.itmonline.org/arts/oldenlandia.htm. Accessed October 21, 2014.

Fong, S., Shoemaker, M., Cadaoas, J., Lo, A., Liao, W., Tagliaferri, M., Cohen, I., Shtivelman, E., 2008. Molecular mechanisms underlying selective cytotoxic activity of BZL101, an extract of Scutellaria barbata, towards breast cancer cells. Cancer Biol. Ther. 7, 577-586. 
Gong T., Wang C.F., Yuan J.R., Li Y., Gu J.F., Zhao B.J., Zhang L., Jia X.B., Feng L., Liu SL, 2015. Inhibition of Tumor Growth and Immunomodulatory Effects of Flavonoids and Scutebarbatines of Scutellaria barbata D. Don in Lewis-Bearing C57BL/6 Mice. Evid. Based Complement. Altern. Med. 2015:630760.

Kaptchuck, T.J., 2000. The web that has no weaver: understanding Chinese medicine. Contemporary Books, Lincolnwood, IL.

Kim, D. I.; Lee, T. K.; Lim, I. S.; Kim, H.; Lee, Y. C.; Kim, C. H., 2005. Regulation of IGF-I production and proliferation of human leiomyomal smooth muscle cells by Scutellaria barbata D. don in vitro: Isolation of flavonoids of apigenin and luteolin as acting compounds. Toxicol. Appl. Pharmacol. 205, 213-224.

Klawitter, J., Klawitter, J., Gurshtein, J., Corby, K., Fong, S., Tagliaferri, M., Quattrochi, L., Cohen, I., Shtivelman, E. Christians, U., 2011. Bezielle (BZL101)-induced oxidative stress damage followed by redistribution of metabolic fluxes in breast cancer cells: a combined proteomic and metabolomic study. Int. J. Cancer 129, 2945-2957.

Li X, Hedge I. Scutellaria barbata D. Don. Available at: http://www.efloras.org/florataxon.aspx?flora_id=2\&taxon_id=200020287. Accessed March 1, 2014.

Marconett, C.N., Morgenstern, T.J., San Roman, A.K., Sundar, S.N., Singhal, A.K., Firestone, G.L., 2010. BZL101, a phytochemical extract from the Scutellaria barbata plant, disrupts proliferation of human breast and prostate cancer cells through distinct mechanisms dependent on the cancer cell phenotype. Cancer Biol. Ther. 10, 397-405.

Perez, A.T., Arun, B., Tripathy, D., Tagliaferri, M.A., Shaw, H.S., Kimmick, G.G., Cohen, I., Shtivelman, E., Caygill, K.A., Grady, D., Schactman, M., Shapiro, C.L., 2010. A phase 1B 
dose escalation trial of Scutellaria barbata (BZL101) for patients with metastatic breast cancer. Breast Cancer Res. Treat. 120, 111-118.

Rugo, H., Shtivelman, E., Perez, A., Vogel, C., Franco, S., Tan Chiu, E., Melisko, M., Tagliaferri, M., Cohen, I., Shoemaker, M., Tran, Z., Tripathy, D., 2007. Phase I trial and antitumor effects of BZL101 for patients with advanced breast cancer. Breast Cancer Res. Treat. 105, $17-28$.

Sato, Y., Suzaki, S., Nishikawa, T., Kihara, M., Shibata, H., Higuti, T., 2000. Phytochemical flavones isolated from Scutellaria barbata and antibacterial activity against methicillinresistant Staphylococcus aureus. J. Ethnopharmacol. 72, 483-488.

Shiau A.L., Shen Y.T., Hsieh J.L., Wu C.L., Lee C.H., 2014. Scutellaria barbata inhibits angiogenesis through downregulation of HIF-1 $\alpha$ in lung tumor. Environ. Toxicol. 29, 363-70.

Shoemaker, M., Hamilton, B., Dairkee, S.H., Cohen, I., Campbell, M.J., 2005. In vitro anticancer activity of twelve Chinese medicinal herbs. Phytother. Res. 19, 649-651.

Wang, B.Y.Y, Wong, H.H.L. An evidence-based perspective of Scutellaria barbata (skullcap) for cancer patients. In: Cho WCS, ed. Evidence-Based Anticancer Materia Medica. Springer Science \& Business Media; 2011:155.

World Health Organization, 2012. Health Service Delivery Profile: China. Available at: http://www.wpro.who.int/health_services/service_delivery_profile_china.pdf?ua=1. Accessed January 20, 2016.

Wu, Y.F., Chen, D.F., 2009. Anti-complementary effect of polysaccharide B3-PS1 in Herba Scutellariae Barbatae (Scutellaria barbata). Immunopharmacol. Immunotoxicol. 31, 696-701. 
Yang J., Yang G., Hou G., Liu Q., Hu W., Zhao P.U., He Y.I., 2015. Scutellaria barbata D. Don polysaccharides inhibit the growth of Calu-3 xenograft tumors via suppression of the HER2 pathway and angiogenesis. Oncol. Lett. 9, 2721-2725.

Yang X., Yang Y., Tang S., Tang H., Yang G., Xu Q., Wu J., 2014. Anti-tumor effect of polysaccharides from Scutellaria barbata D. Don on the 95-D xenograft model via inhibition of the C-met pathway. J. Pharmacol. Sci. 125, 255-63.

Ye, C., Huang, Q., 2012. Extraction of polysaccharides from herbal Scutellaria barbata D. Don (Ban-Zhi-Lian) and their antioxidant activity. Carbohydr. Polym. 89, 1131-1137.

Yeh, Y.C., Chen, H.Y., Yang, S.H., Lin, Y.H., Chiu, J.H., Lin, Y.H., Chen, J.L., 2014. Hedyotis diffusa combined with Scutellaria barbata are the core treatment of Chinese herbal medicine used for breast cancer patients: A population-based study. Evid. Based Complement. Alternat. Med. 2014: 202378.

Yoshida, Y., Wang, M.Q., Liu, J.N., Shan, B.E., Yamashita, U., 1997. Immunomodulating activity of Chinese medicinal herbs and Oldenlandia diffusa in particular. Int. J. Immunopharmacol. 19, 359-370.

Yu, J., Lei, J., Yu, H., Cai, X., Zou, G., 2004. Chemical composition and antimicrobial activity of the essential oil of Scutellaria barbata. Phytochem. 65, 881-884.

Yuan, C., Bieber, E.J., Bauer, B.A., 2011. Traditional Chinese Medicine, CRC Press, New York, NY, USA.

Zhu, B., Wang, H., Eds.; Basic Theories of Traditional Chinese Medicine; Jessica Kingsley Publishers: London, GBR, 2011. 


\section{Appendix A}

Interview questions for TCM practitioners (English Version).

Survey of the Use of Scutellaria barbata/Barbat Skullcap/Ban Zhi Lian by Chinese Practitioners of Traditional Chinese Medicine

About the Practitioners:

Place of education:

Degree(s):

Job Title(s): Years of Experience:

Questions on the use of Scutellaria barbata/barbat skullcap/Ban Zhi Lian:

1. What diseases would you use the herb S. barbata to treat? What are the most common ones?

2. How likely are you to recommend S. barbata for treatment of these diseases? How often would you prescribe it?

3. When would you use S. barbata? (Prevention? Specific disease stage? First line? For specific symptoms?)

4. What other medications (Western or other Chinese herbs) interact with S. barbata?

5. What population would you use or not use this herb in? (Elderly? Children? Pregnant women?)

6. What kinds of therapeutic effects are expected from this herb? What kind of side effects do you expect? How do you treat these side effects?

7. How do you use S. barbata? (Preparation? Formulation? Dosage form?) Please give one formulation you commonly use containing S. barbata and list the other active ingredients with their intended use. (Including amounts)

8. How efficacious is $S$. barbata? Can you give a case example seen in a patient?

9. What diseases would be contraindicative for the use of $S$. barbata? Or, when and why would you discontinue the use of S. barbata in therapy?

10. What do you know about the current research on $S$. barbata? Where do you go to obtain information on S. barbata?

11. What can you tell me about the chemistry of $S$. barbata? (Mechanism of action? Compounds contained?)

12. What are some advantage and disadvantage of TCM in general?

13. What do you think about TCM development in Western countries?

14. In what direction do you think TCM will develop in the future?

15. What do you think about TCM and Western medicine integration in therapy?

16. Would you be interested in receiving a copy of the results once they have been compiled? 


\section{Appendix B}

Interview questions for TCM practitioners (Mandarin Version).

半枝莲的应用/半枝莲在中药上的应用的调查

关于医务人员

教育背景:

学位:

职务:

工作经历:

\section{半枝莲应用的相关问题}

1、你会使用中药半枝莲治疗什么疾病? 最常见的有哪些?

2、你推荐使用半枝莲治疗这些疾病的可能性有多大? 你经常开这个处方吗?

3、何时使用半枝莲？（预防？特定疾病阶段？首先药？特殊症状？）

4、和半枝莲产生相互影响的（中、西药）药物有哪些?

5、针对什么样的人群，你会使用或不使用此中药？（老人？小孩？孕妇？）

6、半枝莲预期会有何种疗效？何种副作用？如何处理治疗这些副作用？

7、如何使用半枝莲？（制剂？配方？使用方式？）请给出一个你常用含有半枝莲 的制剂和其用途的其他活性成分列表。（含量）

8、半枝莲疗效如何？能否提供一例患者案例

9、什么疾病禁忌使用半枝莲? 或者说, 何时、何原因你会在治疗中停用半枝莲?

10、关于当前对半枝莲研究，你了解哪些? 你去哪里获得有关半枝莲的信息?

11、你能告诉我半枝莲的化学成分有哪些？（作用机制？所含化合物？）

12、一旦内容被编译, 你是否有兴趣接收一份副本? 